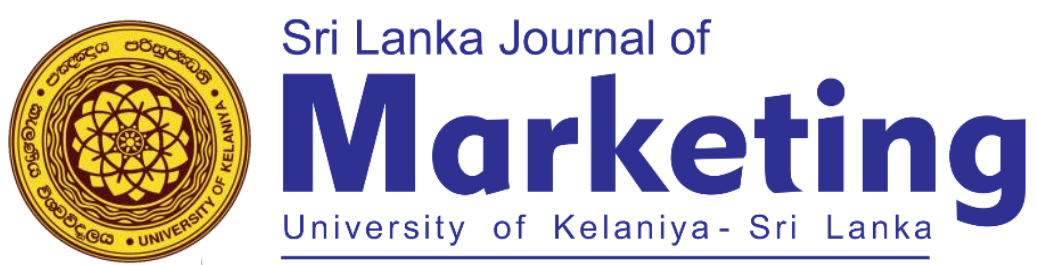

\title{
The Value Creation Determinants of the Global Software Engineering Industry
}

\author{
M.A.S.C Manamendra \\ University of Wales Trinity Saint David, United Kingdom \\ chathuranga.it@gmail.com \\ H.M.R.P Herath \\ Senior Lecturer, University of Kelaniya, Sri Lanka \\ renukaherath@kln.ac.lk
}

DOI: http://doi.org/10.4038/sljmuok.v7i3.74

\begin{abstract}
Every requirement in the software application does not add value to the end users equally where the stakeholders are benefited through them. Majority of the current software engineering practices are formed and done in a value neutral way. With the recent demand for the global software engineering, many organizations have decided to either initiate their own technology centers in the low-cost countries or to partner with outsourced companies to get the benefits of it. However, the practitioners tried applying the traditional software development processes without a proper customization of them to best suit for the distributed teams. Due to the nature of this industry, those traditional processes have further eroded the value with unnecessary checkpoints and gates. This research therefore was carried out to identify the value creation dimensions and their influence creating value with special reference the global software engineering industry. For that, a systematic literature review was carried out and findings were categorized to five areas based on the research questions. They are benefit realization in the delivery process, eliciting and reconciling the requirements for stakeholder value proposition, business case analysis against the business processes, assessment of the value, risk, and opportunity through the frameworks and finally value based monitoring and control through the software development methodology. Mapping the development processes against these areas can change the value addition on the global software engineering industry.
\end{abstract}

Keywords: Global Software Engineering, Software Development Life Cycle, Software Frameworks and Methodologies, Value, Value Based Software Engineering

ORCID of authors: M.A.S.C Manamendra. - (ID https://orcid.org/0000-0002-6614-4002

H.M.R.P Herath - (D) https://orcid.org/0000-0001-8057-0553

Copyright: This is an open access article distributed under the Creative Commons Attribution License 4.0, which permits unrestricted use, distribution, and reproduction in any medium, provided the original work is properly cited. 


\section{INTRODUCTION}

Global business (GB) or International Business (IB) is no longer a new to the business world. With the globalization, many businesses have already started buying and selling goods or services across the borders. In general, GB refers to the exchange of goods or services over a great distance. With the introduction of the internet and other infrastructure majority of the businesses have decided to outsource their regular activities to the low-cost centers which can still provide the same service to their customers. According to Wang (2006) Asia Pacific (APAC) region has been a potential market for the service outsourcing industry due to the cost, limited regulations, availability of the resources, cheap labor and quality of the work. Inkpen \& Ramaswamy (2012) have upheld the same view of Wang (2006) and further discussed the potential for the leading organizations to outsource their software application development and maintenance to the APAC region. It had been predicted by Inkpen and Ramaswamy (2012), Wang (2006) and Portillo-Rodríguez et al. (2012) that the demand for the GSE would be increasing with the introduction of the several outsourcing models by 2016 and beyond. According to the recent census published by Ebert, Kuhrmann and Prikladnicki (2018), the GSE has shown a significant increase in the south Asian region. It is a 42.41\% increase from 2016 to 2019 in Sri Lanka which includes both information technology and business process management industries according to the government census report (Census Dept SL, 2019).

As Udawatta et al., (2019) have highlighted, the GSE/GSD continues to experience a substantial growth by having multiple teams in different geographical locations who get involved in the different phases of the software development life cycle (SDLC). According to Holmstrom et al., (2016) generic models of the software development lifecycles have been built to meet the demands of the collocated development teams, thus they have not been built to support GSE. Having stated that, as Whittle (2019) has pointed out, much of the current software engineering practices is done in a value neutral way which was earlier highlighted by Haile \& Altmann (2016a) as well. When both aspects of the arguments are considered, there are two key areas of research interests that need to be further studied. They are applicability of the generic software development lifecycles in the global setup and assurance of the value delivery throughout the lifecycle. This study aims to address these gaps by identifying key interests related to these two areas through a comprehensive literature analysis in order to provide a meaningful recommendation to determine the value addition determinants in the global software engineering industry.

\section{RESEARCH PROBLEM}

The increasing demand of the globalization has caused the large organizations to reconsider their operating models for them to deliver the software products faster, more frequently and with a higher quality but at a lower cost (Hofstede, 2019). Hence, the global software engineering industry was born 
as an extension to the distributed teams where the overall software engineering practices are carried out by professionals in global teams aiming to achieve a common goal (Ebert et al., 2018). However, this industry is not new and it has been there for the last two decade with many changes (Sanderson, 2017). The related research indicates that the industry is still evolving with respect to its practices, processes, people, and tools. Both success and total failures have been identified. However, the indications or guidelines for application of the right processes to address the challenges in the given context is still unclear. According to Laudicina (2021), perceived value delivery of the current software practices is low in the global teams compared to the collocated teams. Further she has identified three key areas that require further studies with respect to the global teams. i.e. applicability of the continuous software development practices, application of numerical approaches in different phases of software development methodologies and assurance of the value delivery throughout the development cycle. A similar argument is upheld by Paredes-Valverde et al. (2018) where they have argued that the steps in any given process should ensure that the perceived value is not eroded irrespective whether the contributors are distributed or collocated. Additionally, they have highlighted the fact that value neutral nature of software development activities impact to the overall value delivery of a firm. According to Ebert et al. (2018), it is vital to determine the necessity of having certain operations, actions, activities, gates and standards by evaluating key considerations related to the perceived value. However, as Bent \& Dient (2017) have argued, both material and non-material way of creating business value should be in alignment with the overall business process. A similar view is upheld by Espinosa \& Carmel (2018) and they have further highlighted that the software delivery processes are built by heavily focusing on the engineering practices instead of combining the business value along with the engineering demands. This hinders the overall value creation in the global software engineering industry. Therefore, this systematic literature review was carried out aiming to achieve the below three objectives.
a) To identify the influence of delivery process in value creation
b) To identify the influence of existing frameworks in value creation
c) To identify the influence of methodology for value creation in the process of value creation

\section{BACKGROUND AND RELATED WORK}

Software Development Life Cycle (SDLC) is a process used to develop or redesign high quality software system which meets both the customer and the real-world requirement including software testing, analysis and post process maintenance (Ambler \& Lines, 2016). There have been many different models those were introduced in the history of software development industry. Namely they are waterfall model, spiral model, rapid application development, V model, evolutionary prototyping model, and finally agile development model (Kaur \& Sharma, 2014). Each of them has their own pros and cons. As Mazareanu (2020) says, the primary focus of the delivery process is to assure that the end 
users requirements are properly captured, documented, developed, tested and delivered as planned with the expected quality. However, delivering a complete software application or a piece of it has many other aspects to consider. According to Boehm (2003), these models worked well when the software decisions did not have a much of an influence in the overall business models where value-neutral approach has been reasonably workable. But, as both Cavusgil et al. (2014) and Hofstede (2019) have highlighted, nowadays businesses have a direct relationship to the software application delivery process where the cost, schedule, scope and more importantly the value of the have direct impact to the overall business.

Another area that should be focused in the SDLC is the team that gets involved in the delivery process which has been omitted by the existing models stated above. As Sison et al. (2006) argue, if a business wants to understand the return on investment for a software product, the organization and leadership should focus on the strategic link between the software development team and the delivery pipeline. This view is upheld by Edward (2010) and Ebert, Kuhrmann and Prikladnicki (2016). Further, the software products and IT systems or services should be fully focusing on the outcome to assure it adds value to the end user. Professional software engineering practices and the existing models help to realize the customer needs in a methodical way and capture and convert it into a language that can be understood by the engineering teams. Thereafter, it goes through a technical journey until the software product is converted into the final usable product. In a typical SDLC, requirement elicitation, design, development, testing, and maintenance are considered as the critical steps. However, all these steps and their internal activities are considered equally important in the traditional models (Jonsson et al., 2008). As Boehm (2003) argued earlier and both Sison et al. (2006) and Ge (2011) later agreed and proven, many organizations goes wrong when they cannot realize the value of each activity within the process where each decision is based on a value-neutral activities. The same view is upheld by Mazareanu (2020) in his recent research and further added the importance of streamlining the processes around the value delivery. As a result of many research findings Agile principles and values were introduced later to cater to the demand of considering the value in the process. However, as Ge (2011) has argued and later upheld by Lanubile et al. (2019), implementing Agile is not suffice to assure the value is properly created and delivered within the process. Hence, a proper evaluation of the current processes against the value addition and implementation of a better approach is crucial for the GSE industry.

\subsection{Impact of Value Neutral Software Development Practices In GSE}

Nowadays in businesses the software decisions drive the overall system value and corporates are highly dependent on the software applications. But, both software engineering practices as well as the researches related to that are done in a value neutral setting in which each component in the application, the use cases, functionalities, object relationships and even bugs are considered equally important (Ge, 2011). Currently, there is no any holistic methodology or process that focuses on gaining the maximum 
outcome by generating the maximum benefit through the delivery process itself with the available resources (Murtazaev et al., 2010). The same view is upheld by Chen \& Dodd (2016) where they highlight the gap of not integrating the human resources with the goals of the overall software application delivery. These two arguments have been later upheld and further discussed by Espinosa \& Carmel (2018). According to them, nuances of value neutrality in the overall software development lifecycle have cause internal inefficiencies throughout the journey by impacting to the cost and timelines. Further, they argue that analyzing the software functionalities against the potential value and setting a single cohesive pipeline to support the delivery is crucial in nowadays business. As Murtazaev et al. (2010) further argues, the methodologies available and currently used in the industry focus on the technical steps hence the value of the each step is absent which leads to lose the opportunity of costcutting for the corporate. This argument was later upheld by Bent \& Dient (2017) where they have highlighted the importance of customizing the standard process in order to meet the industry specific demands. As Boehm (2013) has proven and later discussed and agreed by both Sanderson (2017) and Hofstede (2019), only by changing the value neutral software testing to value based software testing by eliminating the unnecessary expenditures the GSE could save $\$ 300$ billion a year. According to Huang \& Boehm (2006) the importance of having a holistic approach for the GSE to focus on the value based approach is necessary as release process is dependent on the overall process, not just independent steps. Therefore, value-based requirements engineering, designing, quality management, development and maintenance are the key considerations to assure the value delivery. In the traditional value neutral approach, the software developers are assigned tasks to deliver within a specified time and the same is transferred to the quality assurance process to assure what has been built is according to the specification. The engagement of the end user and feedback loop is absent until the product is ready for a demonstration. Most importantly in modern day businesses the requirements are more volatile due to the nature of the businesses and many environmental factors (Bent \& Dient, 2017). Hence, the frequent feedback loop is crucial for the development team to assure that what is planned to delivery is exactly what the customer wants (Erdogmus et al., 2014). However, as Boehm \& Huang (2003) say due to the lack of focus on identifying the key stakeholders, eliciting the value proposition properly, and setting the right objectives for the development team lead to erode the overall value creation. In absence of a holistic approach, the individual steps in the overall process takes place independently. Only the relationship to the previous step is the task dependency (Noll et al., 2016). This format ignores the reconciliation of the value propositions into a set of objectives which are ultimately converted into achievable architectural solutions (Boehm, 2003).

The primary goal of the software creation is to create either material or non-material business values. But, as Murtazaev et al. (2010) say the primary focus of the software engineers is to only focus on the technical aspects and unknowingly the business aspect is neglected. The same argument is upheld by Hofstede (2019) later where he has provided a counter argument to McSweeney (2016) by highlighting 
Murtazaev et al. (2010)'s argument on having proper mechanisms to assure both material and nonmaterial business values. The challenge in the format is to identify the value upfront and assure it is maintained throughout the delivery process to make sure that the intended piece of software is delivered with the right business value. However, much of the current software practices ignores this evaluation within the delivery process. As Hofstede (2019) and (Lin, 2019) have discussed, the value driven decisions start at the requirement prioritization stage which must be continued to the rest of the steps until the finished product is delivered to the end users. But, due to the nature of the waterfall delivery models, always the relationship between the steps are only technical oriented, hence the value considerations in the technical steps are mostly absent (Yunita et al., 2019).

As a solution, Boehm and Ii (2007) have discussed the usage of earned value technique in the delivery process. However, as they have found, software development stage is complex compared to the other steps in the process as multiple activities are taken place simultaneously and some tasks may be on budget and schedule, some are not. But, traditional earned value system can help to measure the budgeted cost of work scheduled vs budgeted cost of work performed and make decisions on the overall project expenditures to understand the project progress. Lipke et al. (2009) bring a counter argument on using EVM in typical software delivery setup and argue that use of EVM only shows the project performs, but real value assessment is neglected. Hence, the typical EVM system does not help to satisfy the demand of business value delivery through the existing software delivery processes. Both these authors' arguments have been later quoted by (Shen et al., 2018) where they have discussed about simplifying the software engineering process to shorter, but value focused deliveries. Additionally, they have further discussed that current value neutral software delivery process should be converted into the value-based software engineering practices by going beyond basic employee allocations to a specific software delivery activity.

\subsection{Value Based Software Delivery Processes}

Although certain processes are promoted as value based software delivery process, the real value calculation or the assessment is still ambiguous (Murtazaev et al., 2010). However, Tyagi et al. (2015) counter argues that the real value creation is not limited the process, but it has a major impact. When the literature is thoroughly studied, it was noticed that many researchers have studied the steps in the delivery process independently. i.e. value based requirement engineering, value based designing, value based development and value based testing. As Lipke et al. (2009) suggest, the overall process consists of a series of sub activities and the outcome is heavily dependent on each of them. A similar argument is upheld by Hofstede (2019) where he emphasized the importance of having the interconnectivity of the software development activities. According to Grünbacher, Egyed and Medvidovic (2012), refinement of the current practices is much harder as the project management activities are heavily bound to them. Further, they highlight the fact that refining the six steps separately has added additional 
non-value adding activities since the relationships have not been considered. According to Lanubile et al. (2019), value concerns should be bound to the process starting from the beginning. Hence, an integrated approach is necessary to assure the intended value is delivered throughout the delivery process.

Addressing the activities in the SDLC separately, make the GSE much harder as the teams are not collocated. The distributed team structure itself is challenging and by nature it adds many non-value adding activities to the development process due to the unwanted gates and quality checks (Baiden \& Price, 2011). The effect of unintegrated value based software delivery is negatively impacting to the overall value of the software application while the overall team performance and effectiveness are putting down (Haile \& Altmann, 2016b). According to Erdogmus, Favaro and Strigel (2014) the return on investment on software applications typically takes 18 months to 24 months depending on the nature of the products, hence the evaluation of the value neutral activities in the delivery process should be based on the long term value generation. Inadequate facts and information upfront make the project managers' lives harder as the actual value is a prediction based on the realistic assumptions. As Haile \& Altmann (2016a) further highlight, the analyzing the interrelationships is important to suggest an end to end process. Both Laudicina (2021) and Franco et al. (2018) have discussed the importance of injecting the minimum required information into the initial project plans which cover the respective aspects of value concerns as well.

When the challenges are considered in coming up with an integrated value based software delivery process, Erdogmus, Favaro and Strigel (2014) have found that project evaluations primary depends on cost, scope and time, mapping volatile requirements from customer the developer, complicated technical jargons are not understood by everyone, functional organizational hierarchies, and the emerging nature of both requirements and technology. According to Haile \& Altmann (2016) there are two primary challenges in coming up with a common value based model. They are non-cross functional teams and sequential behavior of the delivery processes. Further, Zanoni et al. (2014) have stated that flow of a requirement from the concept to the customer does not have to be sequential, it should be an iterative process until the real value is generated to all the stakeholders. Further, they say that the primary blocker the development teams face these days is the unwanted governance enforced due to the nature of the traditional organizations. In GSE, this has become a crucial factor as the distributed teams are managed by different organizations and each section is managed by separate managers. i.e., Requirements are captured and prioritized by one team, the development work is transferred to another team and the deployments and maintenance are done by another team. As Haile \& Altmann (2016) say, $39 \%$ of the software organizations have outsourced their quality assurance process to a different organization which needs additional agreements, communication and control. In distributed setup, each of these tasks erode the overall value as the time to market is going to be increased. 
According to Eeckhout et al. (2019), heuristic procedures to solve the project staffing issues in the discrete time trade-offs are automatically bound to the value delivery, but ignored in the decision making process in the globally distributed teams. However, as they have further discussed an integrated, team oriented and simplified software delivery framework for the GSE industry can change the overall delivery process and assure the intended value is generated throughout the process without them being eroded drastically due to the process overheads.

\subsection{Direct and Indirect Impact of Software Delivery Process for the Value Addition}

The delivery process helps both project managers and development teams to plan and measure the software delivery activities. In the typical process any idea goes through the requirement elicitation phase, design phase, development phase, testing phase and launching phase. There are no significant differences in collocated teams and distributed teams (Paredes-Valverde et al., 2018). In GSE, the same processes are followed by the distributed teams (Fernandes \& Machado, 2015). However, as Rajala, Westerlund \& Möller (2012) have highlighted and further discussed later by Eeckhout et al. (2019), market orientation and strategic flexibilities are important in any form of delivery processes. As they have found the intern-functional coordination should be based on customer orientation and competitor orientation to assure that what is generated through the software delivery process is needed in the selected market at the given time. However, absence of the delivery process in many business model has been a challenge for the business leaders to align the delivery process in the global setup. Barney, Aurum \& Wohlin (2008) say that adding business value at the early stages but neglecting them during the process has heavily impacted to the ROI of the investments. They have further discussed the direct impact of the relationship between the activities taken place in the software delivery process and argued that none of the existing SDLCs help to assure that delivery processes are aligned to the business models. As a result, the release alignments do not support the value perspectives of the stakeholders. Hence, Espinosa \& Carmel (2013) suggest that the GSE teams should be bound together through a value based delivery process that considers the critical business values in each phase. However, as Lanubile et al. (2010) argue, the delivery processes should have the generic guidelines for the software teams to align and customize based on the contexts and project types. According to Tyagi et al. (2015), stages in the deliver process should be in alignment with the nature of the software engineering practices in the different sector such as product organizations, service organizations or hybrid organizations. Further, Hofstede (2019) has said that the complexities in the process are subjective to the industries, geographies, nature of the products and type of the contracts as well.

With the introduction of the global teams, the researchers and practitioners have proposed many frameworks that can be used in the global setup. Both structured and non-structure teams have started adhering to them with great efforts. However, the value creation in the overall process is still absent as there is no any guideline given for the users to determine if an activity within the process can add values 
to the stakeholders (Kaur \& Sharma, 2014). As Murtazaev et al. (2010) discuss, the approach to design the overall delivery process is heavily dependent on the framework that is chosen because the it provides the yardsticks to requirements engineering, designing, implementation, testing and deploying. The value-based approaches should be considering the evaluation techniques to assure the intended value is created and delivered. A similar view is upheld by Baiden \& Price (2011) where they highlight the effect of integration of proper framework to team effectiveness. According to them, project team integration to a project delivery should be done based on the framework they have chosen along with the proper alignment to the business value. Understanding the goals, determining the right alignment for the delivery and assurance of the intended timeline with the agreed quality are part of the overall framework. Hence, the value creation in the overall delivery process is heavily dependent on the chosen framework.

In addition to that, As Murtazaev et al. (2010) argue, the software frameworks should provide the guidelines for the software teams to follow by adhering to a effective methodology which is considered as part of the delivery process. But the methodologies which are part of the traditional development practices hinders the value creation by adding many non-value adding activities. The nature of this industry has created new ways of working where the global teams must make their own decisions while their counterparts may not be available. Therefore, the methodology should contain the value propositions of each activity against the business requirements (Esper et al., 2010). As Nord, Ozkaya $\&$ Kruchten (2014) have found, the contradictions in frameworks and methodologies impacts the overall delivery process and effectiveness of the delivery becomes lower due to the lack of guidelines within the methodology. Hence, application of the traditional methodologies should be done after a proper evaluation as coordination and strong links between the delivery process and its methodology can decide the overall value creation in this industry.

In summary, as both Laudicina (2021) and Udawatta et al. (2019) have argued on the most of the discussion points raised by Murtazaev et al. (2010), (Esper et al., 2010) and Nord, Ozkaya and Kruchten (2014), the value delivery of the entire software production depend on how well the organisations are changing from the traditional software delivery methods to the newest methodologies as it has already been proven that software delivery processes impact to the overall value delivery immensely.

\section{METHOD}

This research was designed to be systematic literature review to identify the impact of the delivery process in the GSE for value addition. To do that, specific practices in the GSE was studied based on the literature findings and mapping for the value was identified. Two goals were set for the overall research. They are, examining the artefacts of collocated and distributed teams and analyzing the impact of the delivery process for the value addition. 
This research was started with defining a suitable scope which covered the whole industry at the beginning that led to define the research problem, keywords and high-level approach. IEEE, ACM and Google Scholar were used as the databases for the research papers and google books was used to refer the books related to this area. After the initial selection, the keywords, scope and research strategy were refined, and papers were shortlisted based on the amended key objectives. The keywords which were used are global business, value-based software engineering, global software engineering, global software development, value based global software engineering, global teaming, distributed teams, software delivery processes, software development methodologies, software development frameworks and value creation in the software industry. As the search criteria, first preference was given to the journal papers and years were limited to year 2000 - 2019. The written language was limited to English.

\subsection{Filtering Criteria and Inclusion Process}

Based on the set search criteria, the initial search was carried out and the results were filtered out. To further synthesize and summarize, abstracts were read, and papers were categorized as relevant, may be relevant or irrelevant. During the initial search 143 articles were found and based on the initial criteria only 121 were selected. Based on the keywords and relevance criteria, 67 papers were selected for this research and 3 prominent books are used as references. Selected 67 papers were fully read and summarized into the areas of focus based on the identified research keywords. In this process 6 papers were removed as they were irrelevant as the results were unclear or similar researches were already included.

After the comprehensive literature study based on the given criteria, following research framework (refer Figure 1) was formed and further studied with respect to the research background, methodologies, findings, results and conclusions.

Figure 1: Research Framework

IV

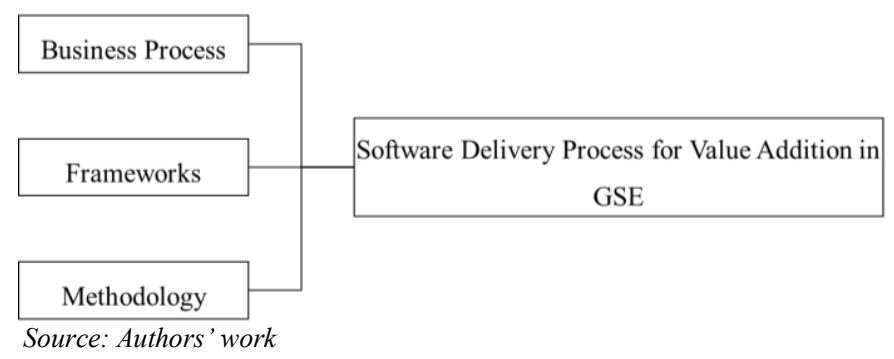

The outcome of this systematic literature review based on the years and framework criteria are included in Table 1 and the detailed categorization of the papers can be seen in Table 2. 
Table 1: Categorization of the Papers

\section{Category}

Short Code

Business process, Global Business, Software lifecycles, Value based business processes

Value creation in software development frameworks, Software

Frameworks, Global teams, Frameworks for global setup,

Frameworks for distributed teams

Value based software development methodology, software methodology, classifications of methodologies

Cat 1

Source: Authors' work

Table 2: Distribution of The Papers Based on The Selected Categories Over the Years

\begin{tabular}{|l|c|c|c|c|c|c|c|c|c|c|c|c|c|c|}
\hline & \multicolumn{3}{|c|}{$2000-2005$} & \multicolumn{3}{|c|}{$2006-2010$} & \multicolumn{3}{c|}{ 2011-2015 } & \multicolumn{3}{c|}{ 2016-2019 } \\
\hline Source & Cat 1 & Cat 2 & Cat 3 & Cat 1 & Cat 2 & Cat 3 & Cat 1 & Cat 2 & Cat 3 & Cat 1 & Cat 2 Cat 3 \\
\hline Google Scholar & 2 & 3 & 1 & 6 & 9 & 4 & 4 & 3 & 5 & 1 & 3 & 2 \\
\hline IEEE & 1 & 1 & 0 & 3 & 2 & 2 & 0 & 0 & 2 & 1 & 0 & 0 \\
\hline ACM & 1 & 0 & 0 & 2 & 1 & 0 & 0 & 0 & 1 & 1 & 0 & 0 \\
\hline Total & 4 & 4 & 1 & 11 & 12 & 6 & 4 & 3 & 8 & 3 & 3 & 2 \\
\hline
\end{tabular}

Source: Authors'work

\section{FINDINGS AND DISCUSSION}

The findings of the literature highlighted the direct relationship in between the value addition and the overall software delivery process. Based on the literature findings and generally available information about the existing software delivery frameworks and methodologies, the justifications on achieving the three objectives are given below.

\section{OBJ1 : Identifying the influence of delivery process in value creation}

\subsection{Benefit Realization in The Delivery Process}

Many software projects fail due to the lack of focus for the actual benefits that are going to be the outcomes. Any organization that focuses on the profitability and value creation for the respective stakeholders should focus on the benefit realization upfront in order to understand the success in profitability or market capitalization (Lanubile et al., 2019). However, the according to the literature findings, many businesses build the software based on the assumption that benefits will automatically come once it is deployed.

\subsection{Eliciting And Reconciling the Requirements for Stakeholder Value Proposition}

As the software delivery process begins with an idea, the requirement should be thoroughly evaluated based on the market conditions, context and the development timelines (Immonen et al., 2016). As Holmstrom et al. (2016) highlight, in the global setup the development teams may be located in different temporal, geographical or socio-cultural locations where the business idea might not be valuable at all. 
Therefore, the implementation would be based on the assumptions that have been made. As they further highlight, the GSE teams might not understand the real stakeholders' expectation without a proper explanation. Further, Ebert, Kuhrmann \& Prikladnicki (2016) argue that much of the software application development activities fail due to the inexpressible and incompatible requirements that are taken through the development process where the set objectives are not clear to all the individuals in the development process. As Hofstede (2019) has argued, the right priority should be given based on the expected revenues targeting to the anticipated customers and delivery roadmap should be clearly aligned to the ROI. Therefore, eliciting the requirements properly and reconciling them based on the expected clashes during the process is a key for the success of the business.

\subsection{Business Case Analysis Against the Business Processes}

According to Kaur \& Sharma (2014) due to the nature of GSE, different organizations use their own business processes. As they have highlighted, the individuals from different time zones, nationals, or different geographical locations work together on different activities that take place within their respective business processes. Fail to realize the communication gaps, coordination issues or other cultural challenges up front may lead the whole business initiative to a waste. As Dumitriu, Oprea \& Mesnita (2011) have found, 39\% of the new projects have failed due to the mismatches in delivery process and the overall business process. They suggest initiating the projects keeping the ROI in mind and at the same time factoring the uncertainties and unseen risks due to the nature of the GSE. Additionally, the misalignment of the capacity planning, resource alignment, frequent inspections, controlling and monitoring in the business process has caused to reduce the value delivery immensely (Lanubile et al., 2019). As they have further highlighted, at any given time, the delivery goals should be aligned to the respective organizational goals. Therefore, the in the global teams, impact of business process with respect to the value delivery is significant factor.

OBJ2: Identifying the influence of existing frameworks in value creation.

\subsection{Assessment of the Value, Risk, And Opportunity through the Frameworks}

The business value of the idea should be analyzed along with the its risk and the opportunity (Little, 2004). As he suggested, the whole idea is depended on staff effectiveness, value assumed, value created, delivery time and resources. According to Grissom et al. (2017), there are two factors that should be considered when assigning the development activities. They are productivity and efficiency. The effective team productivity is heavily depended on the software delivery framework that is being used and it affects the value creation as well due to the market delay costs as they have further said. Little (2004) further argues that relative market value and the gross value capture can vary due to the delivery process which are part of the software frameworks. As Ebert, Kuhrmann \& Prikladnicki (2016) highlight, the use of planned driven development frameworks against the adaptive approaches is heavily 
debated in the literature as assessment of the software risk against the expected value generation is tough with the current frameworks. They have suggested a risk exposure assessment against the assumed value to be mapped with the current framework to assess the delivery timeline and risk of missing the same to avoid the last-minute surprises. However, Noll, Beecham \& Richardson (2016) argue that in GSE, the framework itself has challenges and working on the numbered approach for value realization is much harder than the collocated development practices. Further, they suggest a concurrent and continuous value assessment within the framework to assure the value delivery.

\section{OBJ3: Identifying the influence of methodology for value creation in the process of value creation}

\subsection{Value Based Monitoring and Control Through the Software Development Methodology}

The primary goal of the project managers is to assure the software applications, features of pieces of features are developed and delivered within the budget and timelines (Ambler \& Lines, 2016). As Herbsleb (2007) suggests, the earned value management process is good approach that project managers can use to track the project against the set plans. But as he further says this does not have any relationship to the value being earned by following that plan. The same view is upheld by Rajala, Westerlund \& Möller (2012) and they have suggested a business case oriented monitoring and control mechanism where the evaluations are based on the intended value. i.e. at each milestone, the respective business owners and project managers sit together to evaluate to see if the intended value is generated after a particular step to take the corrective actions if it is not. According to Eeckhout et al. (2019), continuous monitoring, milestone planning, goal based resource alignment and mapping, and value based staffed assignment are crucial to assure the value delivery. However, in the global setup challenges are different and forming a generic methodology to evaluate the value in the software delivery process is practically impossible (Dumitriu et al., 2016). Therefore, a customized methodology is crucial for the business to assure the intended value is not eroded and, in case, if there is a deviation, there should be a mechanism to make corrective actions.

\section{CONCLUSION AND FUTURE WORK}

The GSE is still an evolving industry where the leading organizations from the developed countries are locating their technology centers in the low-cost countries or sign agreements with the outsourced parties in the other geographical areas to support their business processes. During the last two decades, the demand and attention for the GSE was significantly increased due to various reasons. However, value addition in this industry has been a challenging factor due to the nature of GSE. In this article, the focus was to identify if there is any impact to the value addition in the GSE due to the software development processes and present it with the facts. 
The development process is a critical fact in the software delivery as it guides both business and the development teams to ensure that the intended business objectives are met at the right time with the right quality. However, the findings of this research show that either value is not considered in the popular development processes or purposefully ignored them due to challenges in measuring them. Majority of the development processes have not been found to cater to the requirement of the distributed teams. The traditional software application development processes and guidelines have been formed to support the collocated teams to delivery what is assigned to them. But, with the distributed teams the challenges vary due to the time zone differences, communication gaps, geographical issues as well as the socio-cultural issues. Therefore, those traditional processes should be changed to address the challenges within the GSE and then to assure the value addition.

The changes to the existing processes should be further evaluated against the value implications and adjustments should be proposed based on the outcomes which requires a complete assessment of the GSE industry as a whole and other critical success factor for value delivery.

\section{REFERENCES}

Ambler, S., \& Lines, M. (2016). Disciplined agile delivery. https://sistemas.uniandes.edu.co/images/forosisis/foros/fisw 1/1er-Foro-ISW-presentacion-7.pdf

Baiden, B. K., \& Price, A. D. F. (2011). The effect of integration on project delivery team effectiveness. International Journal of Project Management, 29(2), 129-136. https://doi.org/10.1016/j.ijproman.2010.01.016

Barney, S., Aurum, A., \& Wohlin, C. (2008). A product management challenge: Creating software product value through requirements selection. Journal of Systems Architecture, 54(6), 576-593. https://doi.org/10.1016/j.sysarc.2007.12.004

Bent, R., \& Dient, S. (2017). What is House of Quality / QFD Example. https://www.whatissixsigma.net/houseof-quality-qfd/

Boehm, B. (2003a). Value-based software engineering: reinventing. SIGSOFT Software Engineering Notes, 28(2), 3-. https://doi.org/10.1145/638750.638775

Boehm, B. (2003b). Value based software engineering. March, 33-41.

Boehm, B. (2007). Determining How Much Software Assurance Is Enough? A Value-based Approach LiGuo Huang 3 . Cost of "Reduced Delivered Defect Density ": COQUALMO. 1-5.

Boehm, B. (2013). Value-Based Software Engineering. 28(2), 1-12.

Boehm, B., \& Huang, L. (2003). Value-Based Software Engineering: Reinventing "Earned Value" Monitoring and Control. ACM SIGSOFT Software Engineering Notes, 28(2), 3. https://www.researchgate.net/publication/251219436

Cavusgil, S. T., Knight, G., Riesenberger, J. R., Rammal, H. G., \& Rose, E. L. (2014). International Business. Pearson Australia. https://books.google.lk/books?id=KcSaBQAAQBAJ 
Census, G. (2019). of Sri Lank a Information Technology.

Chen, S., \& Dodd, J. L. (2016). Economic Value Added ( EVA ${ }^{T M}$ ): An Empirical Examination Of A New Corporate Performance Measure. 9(3), 318-333.

Dumitriu, F., Oprea, D., \& Mesnita, G. (2016). Issues and strategy for agile global software development adoption. Recent Researchers in Applied Economics, WSEAS, 37-42. http://140.115.155.41/agilemethod/download/2011papers/2011 Issues and Strategy for Agile Global Software Development Adoption/Issues and Strategy for Agile Global Software Development Adoption.pdf

Ebert, C., Kuhrmann, M., \& Prikladnicki, R. (2018). Global software engineering: Evolution and trends. Proceedings - 11th IEEE International Conference on Global Software Engineering, ICGSE 2016. https://doi.org/10.1109/ICGSE.2016.19

Edward, R. (2010). Stockholders and Stakeholders : A New Perspective on Corporate Governance.

Eeckhout, V. Den, Maenhout, M. B., \& Vanhoucke, M. (2019). A heuristic procedure to solve the project staffing problem with discrete time/resource trade-offs and personnel scheduling constraints. Computers and Operations Research, 101, 144-161. https://doi.org/10.1016/j.cor.2018.09.008

Erdogmus, H., Favaro, J., \& Strigel, W. (2014). Guest editors' introduction: Return on investment. IEEE Software, 21(3), 18-22. https://doi.org/10.1109/MS.2004.1293068

Esper, T. L., Ellinger, A. E., Stank, T. P., Flint, D. J., \& Moon, M. (2010). Demand and supply integration: A conceptual framework of value creation through knowledge management. Journal of the Academy of Marketing Science, 38(1), 5-18. https://doi.org/10.1007/s11747-009-0135-3

Espinosa, J. A., \& Carmel, E. (2018). The impact of time separation on coordination in global software teams: A conceptual foundation. Software Process Improvement and Practice, 8(4), 249-266. https://doi.org/10.1002/spip.185

Fernandes, J. M., \& Machado, R. J. (2015). Software Business. 6th International Conference, ICSOB 2015 Braga, Portugal, June 10-12, 2015 Proceedings, June, 167-173. https://doi.org/10.1007/978-3-642-136337

Franco, E. F., Hirama, K., \& Carvalho, M. M. (2018). Applying system dynamics approach in software and information system projects: A mapping study. Information and Software Technology, 93, 58-73. https://doi.org/10.1016/j.infsof.2017.08.013

Ge, K. (2011). Value creation in e-Business. Asia Pacific Journal of Clinical Nutrition, 20(3), 439-446. https://doi.org/10.1002/smj.187

Grissom, J. A., Kalogrides, D., \& Loeb, S. (2017). Strategic Staffing? How Performance Pressures Affect the Distribution of Teachers Within Schools and Resulting Student Achievement. American Educational Research Journal, 54(6), 1079-1116. https://doi.org/10.3102/0002831217716301

Grünbacher, P., Egyed, A., \& Medvidovic, N. (2012). Reconciling software requirements and architectures with intermediate models. Software \& Systems Modeling, 3(3), 235-253. https://doi.org/10.1007/s10270-0030038-6

Haile, N., \& Altmann, J. (2016a). Structural analysis of value creation in software service platforms. Electronic Markets, 26(2), 129-142. https://doi.org/10.1007/s12525-015-0208-8

Haile, N., \& Altmann, J. (2016b). Value creation in software service platforms. Future Generation Computer Systems, 55(November 2017), 495-509. https://doi.org/10.1016/j.future.2015.09.029 
Haile, N., \& Altmann, J. (2016c). Value creation in software service platforms. Future Generation Computer Systems, 55(October), 495-509. https://doi.org/10.1016/j.future.2015.09.029

Hofstede, G. (2019). Dimensions do not exist: A reply to Brendan McSweeney. Human Relations, 55(1), 1-8.

Holmstrom, H., Conchúir, E. Ó., Ågerfalk, P. J., \& Fitzgerald, B. (2016). Global software development challenges: A case study on temporal, geographical and socio-cultural distance. Proceedings - 2006 IEEE International Conference on Global Software Engineering, ICGSE 2006, February 2014, 3-11. https://doi.org/10.1109/ICGSE.2006.261210

Huang, L., \& Boehm, B. (2006). How much Investment Is Enough : A Value-Based Approach. Software, IEEE, 23(5), 88-95.

Immonen, A., Ovaska, E., Kalaoja, J., \& Pakkala, D. (2016). A service requirements engineering method for a digital service ecosystem. Service Oriented Computing and Applications, 10(2), 151-172. https://doi.org/10.1007/s11761-015-0175-0

Inkpen, A., \& Ramaswamy, K. (2012). Global Strategy: Creating and Sustaining Advantage across Borders. Oxford University Press. https://books.google.lk/books?id=6iPxiNCNIWgC

James D, H. (2007). Global software engineering: The future of socio-technical coordination. FoSE 2007: Future of Software Engineering, February, 188-198. https://doi.org/10.1109/FOSE.2007.11

Jonsson, K., Westergren, U., \& Holmström, J. (2008). Technologies For Value Creation: An Exploration Of Ubiquitous Computing In Business Networks. Working Paper, 107-131.

Kaur, P., \& Sharma, S. (2014). Agile Software Development in Global Software Engineering. International Journal of Computer Applications, 97(4), 39-43. https://doi.org/10.5120/16999-7181

Lanubile, F., Ebert, C., Prikladnicki, R., \& Vizcano, A. (2019). Collaboration tools for global software engineering. IEEE Software, 27(2), 52-55. https://doi.org/10.1109/MS.2010.39

Laudicina, P. A. (2021). Investor sentiments at the onset of the COVID-19 crisis highlight the urgent need for strategic foresight capabilities in an age of external shocks, mounting complexities, and growing risks. https://www.kearney.com/foreign-direct-investment-confidence-index/2020-full-report

Lin, H.-J. (2019). Kano Model Analysis in Product Design. https://uxplanet.org/kano-model-analysis-inproduct-design-7a3cca3e51ed

Lipke, W., Zwikael, O., Henderson, K., \& Anbari, F. (2009). Prediction of project outcome. The application of statistical methods to earned value management and earned schedule performance indexes. International Journal of Project Management, 27(4), 400-407. https://doi.org/10.1016/j.ijproman.2008.02.009

Little, T. (2004). Value creation and capture: A model of the software development process. IEEE Software, 21(3), 48-53. https://doi.org/10.1109/MS.2004.1293072

Mazareanu, E. (2020). Global outsourcing market size 2019. https://www.statista.com/statistics/189788/globaloutsourcing-market-size/

Murtazaev, A., Kang, S., Baik, J., \& Lee, J. (2010). An approach to defining a value-based software development process. Proceedings - 9th IEEE/ACIS International Conference on Computer and Information Science, ICIS 2010, 690-695. https://doi.org/10.1109/ICIS.2010.79

Noll, J., Beecham, S., \& Richardson, I. (2016). Global software development and collaboration. ACM Inroads, 1(3), 66. https://doi.org/10.1145/1835428.1835445

Nord, R. L., Ozkaya, I., \& Kruchten, P. (2014). Agile in Distress: Architecture to the Rescue. 43-57. 
https://doi.org/10.1007/978-3-319-14358-3_5

Paredes-Valverde, M. A., Salas-Zárate, M. del P., Colomo-Palacios, R., Gómez-Berbís, J. M., \& ValenciaGarcía, R. (2018). An ontology-based approach with which to assign human resources to software projects. Science of Computer Programming, 156, 90-103. https://doi.org/10.1016/j.scico.2018.01.003

Portillo-Rodríguez, J., Vizcaíno, A., Piattini, M., \& Beecham, S. (2012). Tools used in Global Software Engineering: A systematic mapping review. Information and Software Technology, 54(7), 663-685. https://doi.org/10.1016/j.infsof.2012.02.006

Rajala, R., Westerlund, M., \& Möller, K. (2012). Strategic flexibility in open innovation - designing business models for open source software. European Journal of Marketing, 46(10), 1368-1388. https://doi.org/10.1108/03090561211248071

Sanderson, Z. (2017). Global Software Development and the Early Stages of Offshoring Bachelor of Science Thesis in Software Engineering and Management.

Shen, X. N., Minku, L. L., Marturi, N., Guo, Y. N., \& Han, Y. (2018). A Q-learning-based memetic algorithm for multi-objective dynamic software project scheduling. Information Sciences, 428, 1-29. https://doi.org/10.1016/j.ins.2017.10.041

Sison, R., Jarzabek, S., Ow, S., Rivepiboon, W., \& Hai, N. (2006). Software practices in five ASEAN countries: An exploratory study. Proceedings - International Conference on Software Engineering, 2006, 628-631. https://doi.org/10.1145/1134378

Tyagi, S., Choudhary, A., Cai, X., \& Yang, K. (2015). Value stream mapping to reduce the lead-time of a product development process. International Journal of Production Economics, 160, 202-212. https://doi.org/10.1016/j.ijpe.2014.11.002

Udawatta, C. S., Devapriya, K. A. K., Gowsiga, M., \& Thatshayini, P. (2019). An investigation into value addition concept correlated to facilities management. November, 56-65. https://doi.org/10.31705/wcs.2019.6

Wang, J. (2006). Public diplomacy and global business. Journal of Business Strategy, 27(3), 41-49. https://doi.org/10.1108/02756660610663826

Whittle, J. (2019). Is Your Software Valueless? IEEE Software, 36(3), 112-115. https://doi.org/10.1109/MS.2019.2897397

Yunita, D., Ayshwarya, B., Ridhawati, E., Huda, M., Hashim, A., Teh, K. S. M., Nguyen, P. T., Shankar, K., \& Maseleno, A. (2019). Application of analytical hierarchy process method in laptop selection. International Journal of Recent Technology and Engineering, 8(2 Special Issue 3), 1603-1607. https://doi.org/10.35940/ijrte.B1291.0782S319

Zanoni, M., Perin, F., Fontana, F. A., \& Viscusi, G. (2014). Pattern detection for conceptual schema recovery in data-intensive systems. Journal of Software: Evolution and Process, 26(12), 1172-1192. https://doi.org/10.1002/smr 